Research Paper

\title{
Characteristics of mortal COVID-19 cases compared to the survivors
}

\author{
Xianghui Zhou ${ }^{1,2, *}$, Zhipeng Cheng ${ }^{1,2, *}$, Dan Shu ${ }^{3}$, Wenyi Lin ${ }^{1,2}$, Zhangyin Ming ${ }^{3,4}$, Wei Chen ${ }^{6, \&}$, \\ Yu Hu${ }^{1,2,5}$ \\ ${ }^{1}$ Department of Hematology, Union Hospital, Tongji Medical College, Huazhong University of Science and \\ Technology, Wuhan 430022, China \\ ${ }^{2}$ Collaborative Innovation Center of Hematology, Huazhong University of Science and Technology, Wuhan 430022, \\ Hubei, China \\ ${ }^{3}$ Department of Pharmacology, School of Basic Medicine, Tongji Medical College of Huazhong University of \\ Science and Technology, Wuhan 430022, China \\ ${ }^{4}$ Tongji-Rongcheng Center for Biomedicine, Huazhong University of Science and Technology, Wuhan 430022, China \\ ${ }^{5}$ Hubei Clinical Medical Center of Cell Therapy for Neoplastic Disease, Wuhan 430022, Hubei, China \\ ${ }^{6}$ Laboratory of Vaccine and Antibody Engineering, Beijing Institute of Biotechnology, Beijing 100071, China \\ *Equal contribution
}

Correspondence to: Yu Hu, Wei Chen; email: dr huyu@126.com, https://orcid.org/0000-0002-2815-4568; cw0226@foxmail.com

Keywords: coronavirus disease 2019, COVID-19, SARS-CoV-2, death cases, survival cases

Received: May 21, $2020 \quad$ Accepted: October 1, $2020 \quad$ Published: November 21, 2020

Copyright: (C) 2020 Zhou et al. This is an open access article distributed under the terms of the Creative Commons Attribution License (CC BY 3.0), which permits unrestricted use, distribution, and reproduction in any medium, provided the original author and source are credited.

\section{ABSTRACT}

The outbreak of coronavirus disease 2019 (COVID-19) initially occurred in December 2019 and triggered a public health emergency. The increasing number of deaths due to this disease was of great concern. Therefore, our study aimed to explore risk factors associated with COVID-19 deaths.

After having searched the PubMed, EMBASE, and CNKI for studies published as of August 10, 2020, we selected articles and extracted data. The meta-analysis was performed using Stata 16.0 software.

Nineteen studies were used in our meta-analysis. The proportions of comorbidities such as diabetes, hypertension, malignancies, chronic obstructive pulmonary disease, cardio-cerebrovascular disease, and chronic liver disease were statistically significantly higher in mortal COVID-19 cases. Coagulation and inflammatory markers, such as platelet count, D-dimer, prothrombin time, C-reactive protein, procalcitonin, and interleukin 6, predicted the deterioration of the disease. In addition, extracorporeal membrane oxygenation and mechanical ventilation predicted the poor prognosis during its progression.

The COVID-19 pandemic is still evolving, placing a huge burden on healthcare facilities. Certain coagulation indicators, inflammatory indicators, and comorbidities contribute to the prognosis of patients. Our study results may help clinicians optimize the treatment and ultimately reduce the mortality rate.

\section{INTRODUCTION}

In late December 2019, a cluster of cases of "pneumonia of unknown cause" were reported in Wuhan, China. These patients were epidemiologically linked to a seafood and wildlife wholesale market. The initial diagnosis was pneumonia of an unknown etiology [1]. The National Health Commission of the People's Republic of China announced that a novel coronavirus, which is now renamed as severe acute respiratory syndrome coronavirus 2 (SARS-CoV-2) by the World Health Organization, was responsible for the global outbreak [2]. This causative pathogen SARSCoV-2 has been identified as a novel enveloped RNA 
beta coronavirus [3]. Coronaviruses $(\mathrm{CoVs})$ primarily target the human respiratory system and cause severe acute respiratory syndrome (SARS) and the Middle East respiratory syndrome (MERS). More importantly, Coronavirus disease (COVID-19) shares many similar clinical symptoms with SARS-CoV and MERS-CoV [2]. For instance, infected patients predominantly present with fever, cough, and radiological ground-glass lung opacities [4]. SARS-CoV-2 has gradually spread worldwide, and the disease caused by this virus, named COVID-19, is now a pandemic. The rapid increase in the transmission of this virus is mainly due to direct contact with infected people through respiratory droplets and touching contaminated objects. Moreover, the virus can be spread by asymptomatic carriers [5]. As of August 14, 2020, 20,730,456 laboratory-confirmed cases and 751,154 deaths in 216 countries, regions, or territories have been documented [https://www.who.int (accessed 14 August 2020)].

Since the outbreak, several medical centers worldwide have collected data (epidemiological data, clinical patient data etc.) on relevant cases, and medical teams have focused their efforts into finding a treatment for COVID-19. Many studies have been published in a timely manner to provide the public with a real-time understanding of COVID-19. China is one of the main epidemic areas of COVID-19, from where some clinical data have been summarized. Certain studies also determined that an updated analysis of cases throughout mainland China could help identify the defining clinical characteristics and severity of COVID-19. A previous study showed that 7,736 COVID-19 patients had been hospitalized in 30 provinces, autonomous regions, or municipalities across China as of January 29, 2020 [6]. The median age of these patients was 47 years, and fever and cough were the most common symptoms. On admission, ground-glass opacity was the most common radiologic finding on chest computed tomography (CT) (56.4\%). No radiographic or CT abnormality was found in 157 of 877 patients (17.9\%). Clinical data from hospitals nationwide are gradually being published. Some retrospective studies investigated the specificity and sensitivity of imaging, nucleic acid detection, feasibility of multiple treatments (e.g., convalescent plasma therapy and antiviral therapy), and clinical characteristics of both critical and non-critical patients. These clinical characteristics were compared between mortal and survival cases [7-10]. Besides, several systematic reviews have summarized such comparisons (e.g., imaging findings, laboratory test results, and clinical symptoms). However, only limited data on clinical characteristics of mortal cases and treatment outcomes of critical COVID-19 cases are available because of the relatively small numbers of nonsurvivors in previous studies. Very few systematic reviews of mortality risk factors in COVID-19 patients have been conducted, although they are of great importance to reduce mortality.

As COVID-19-related mortality continues to grow worldwide, increasing attention has been paid to summarizing the findings and complications obtained from clinical signs, laboratory and chest CT, and treatments that mortal cases received. We conducted this meta-analysis to provide a comprehensive understanding of the characteristics of COVID-19-related deaths and compare them with those of survivors to enable better investigations of the prognostic factors of COVID-19 in infected individuals. Our study results are expected to provide evidence on specific risk factors of COVID-19 and aid in reducing its associated fatality.

\section{RESULTS}

\section{Literature search and screening}

The database searches identified a total of 4,896 potentially relevant articles, including 4375 in PubMed, 298 in EMBASE, and 60 in CNKI. Of these articles, 141 were excluded due to duplication. After screening titles and abstracts, we further excluded 4437 due to non-relevance. After full texts were carefully reviewed, 113 articles were removed for not reporting clinical features of COVID-19 or describing death cases, or for some other reasons (Supplementary File 1). Forty-two articles were included in the metaanalysis, of which 8 articles did not provide a detailed clinical description of death cases and cured ones, and 6 articles only described fatal cases. Besides, 6 articles reported a study conducted in the same medical center, and 3 articles had sample sizes of $<60$ participants. Finally, the meta-analysis included 19 eligible articles [11-29]. The flow diagram (Figure 1) illustrates the detailed procedure of literature search.

\section{Characteristics of studies and demographic features}

Of 19 studies included in the meta-analysis, some were conducted in Asia, some in Europe, and the others in the Americas. Their sample sizes varied between 100 and 7,371 participants (Table 1). These studies showed that the proportion of male was significantly higher in the death group than that in the survival group (odds ratio $[\mathrm{OR}]=1.68,95 \%$ confidence interval $[\mathrm{CI}]$ : 1.36-2.08, $P<0.001)$. Furthermore, the mean age of the death group ranged from 65.6 to 78.7 years, compared to 46-68.7 years in the survival group. According to the metaanalysis results, the death group had an older mean age than the survival group (mean difference $[\mathrm{MD}]=12.38$, 95\% CI: 10.82-13.95, $P<0.001)$. Considering the high heterogeneity of age and gender estimates across 19 
studies, we used the random-effects model (Tables 2, 3 and Supplementary Figure 1).

\section{Clinical symptoms}

According to the meta-analysis of included studies, the death group had statistically significant higher proportions of patients with sputum $(\mathrm{OR}=1.30,95 \% \mathrm{CI}$ : 1.04-1.60, $P=0.02)$, fatigue $(\mathrm{OR}=1.65,95 \% \mathrm{CI}: 1.01$ 2.66, $P=0.04)$, and dyspnea $(\mathrm{OR}=1.88,95 \% \mathrm{CI}: 1.16$ 3.03, $P=0.01$ ) than the survival patients. Furthermore, the heterogeneity was high for fatigue $\left(\mathrm{I}^{2}=85.99 \%\right.$, $P<0.1)$ and dyspnea $\left(\mathrm{I}^{2}=66.89 \%, P<0.1\right)$. Thus, the random-effects model was used for the analyses. For sputum, we used the fixed-effects model because the heterogeneity was low $\left(\mathrm{I}^{2}<50 \%\right)$ and the Q statistic for the test of heterogeneity indicated statistical nonsignificance $(P>0.1)$.

The death group had a higher proportion of hemoptisis than the survival group $(\mathrm{OR}=1.40,95 \% \mathrm{CI}: 0.66-2.97$, $P=0.38$ ). However, the former group had lower proportions of fever $(\mathrm{OR}=0.84,95 \% \mathrm{CI}$ : $0.57-1.21$, $P=0.34)$, cough $(\mathrm{OR}=0.87,95 \% \mathrm{CI}: 0.56-1.35, P=0.54)$, headache $(\mathrm{OR}=0.75,95 \% \mathrm{CI}: 0.40-1.42, P=0.38)$, myalgiaor $(\mathrm{OR}=0.94,95 \% \mathrm{CI}: 0.73-1.23, P=0.68)$, diarrhea $(\mathrm{OR}=0.68, \quad 95 \% \quad \mathrm{CI}: \quad 0.39-1.19, \quad P=0.18)$, nausea/vomiting $\quad(\mathrm{OR}=0.83,95 \% \quad \mathrm{CI}$ : $0.52-1.34$, $P=0.44)$, and sore throat $(\mathrm{OR}=0.61,95 \%$ CI $0.35-1.06$, $P=0.08)$ than the latter group. All of these differences showed no statistical significance. With regard to myalgiaor, nausea/vomiting, and sore throat, as the

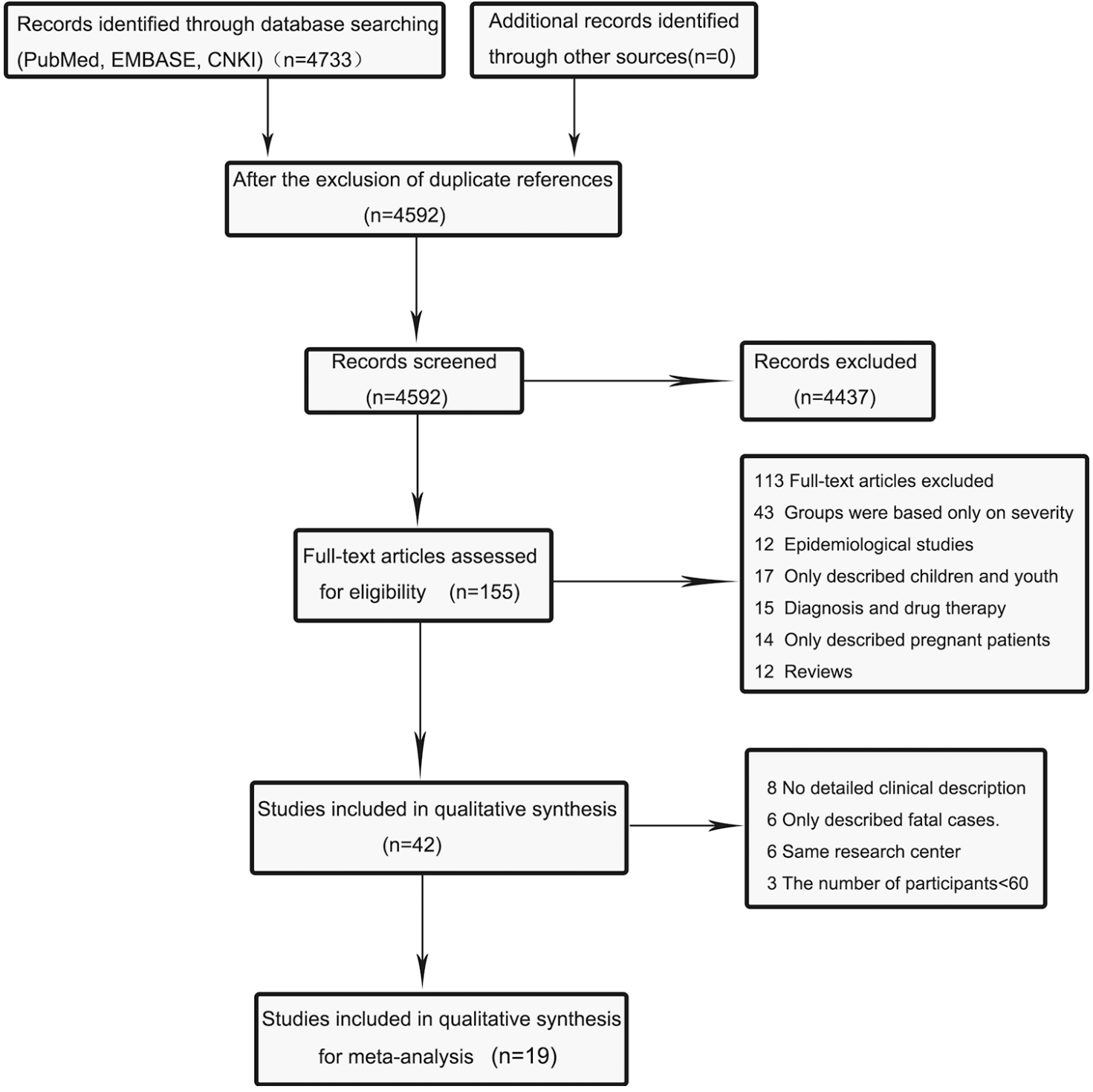

Figure 1. Flow diagram of the literature search and selection process in the meta-analysis. 
Table 1. Main characteristics of the included studies in our-analysis.

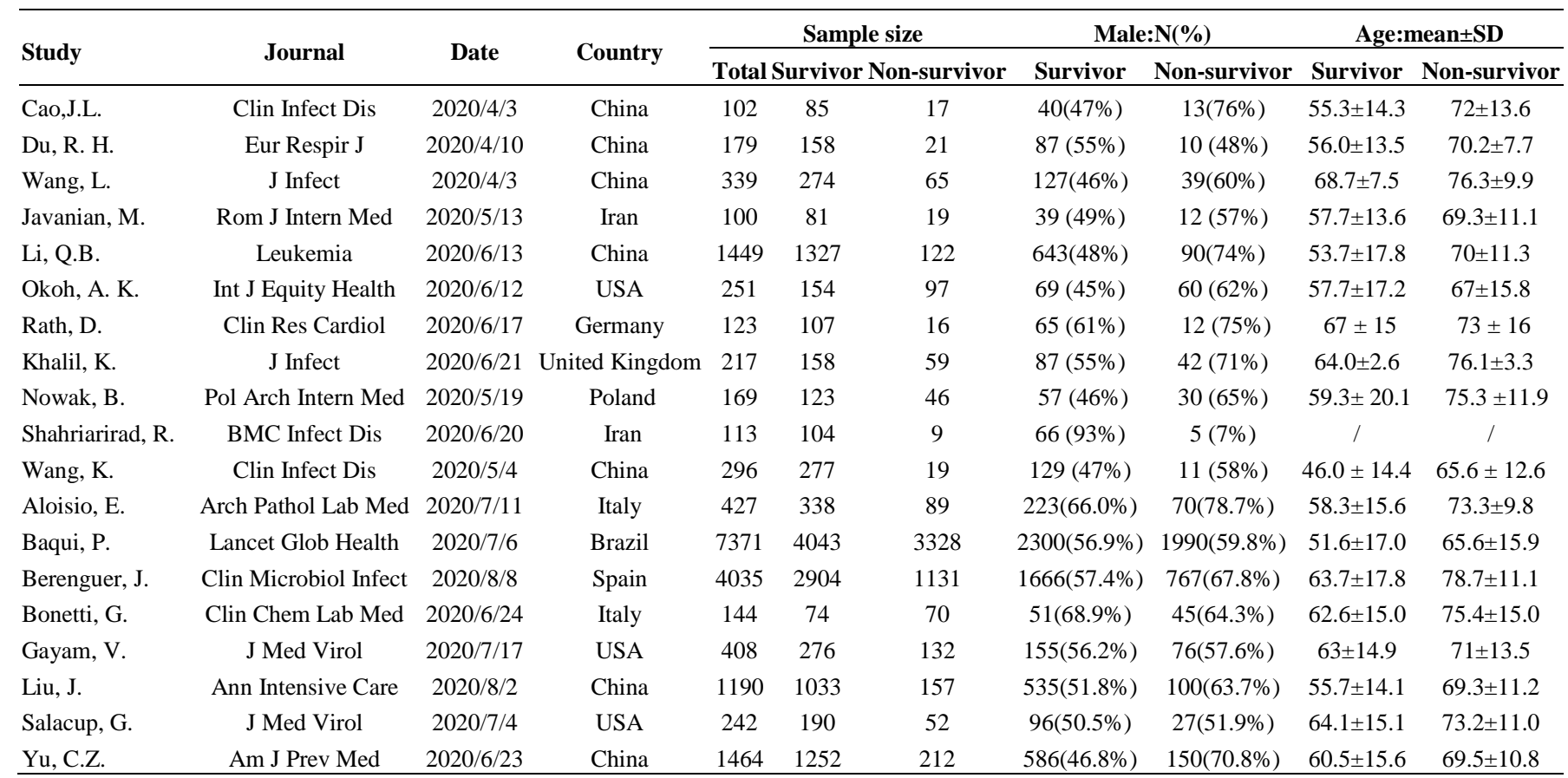

Table 2. Results of meta-analysis (binary variable).

\begin{tabular}{|c|c|c|c|c|c|c|c|}
\hline \multirow[b]{2}{*}{ Variable } & \multirow{2}{*}{$\begin{array}{c}\text { No. of } \\
\text { Studies }\end{array}$} & \multirow[b]{2}{*}{ OR } & \multirow[b]{2}{*}{$95 \% \mathrm{CI}$} & \multirow[b]{2}{*}{ P-Value } & \multicolumn{2}{|c|}{ Heterogeneity } & \multirow[b]{2}{*}{ Model } \\
\hline & & & & & $\mathrm{I}^{2}$ & p & \\
\hline Gender-male & 19 & 1.68 & $1.36,2.08$ & $<0.001$ & $78.50 \%$ & 0.00 & Random \\
\hline China & 7 & 2.25 & $1.55,3.25$ & $<0.001$ & $66.18 \%$ & 0.01 & Random \\
\hline Others & 12 & 1.40 & $1.16,1.68$ & $<0.001$ & $57.37 \%$ & 0.00 & Random \\
\hline Fever & 11 & 0.84 & $0.57,1.21$ & 0.34 & $59.37 \%$ & 0.01 & Random \\
\hline China & 6 & 0.95 & $0.51,1.77$ & 0.87 & $69.55 \%$ & 0.01 & Random \\
\hline China & 7 & 0.99 & $0.51,1.90$ & 0.97 & $87.51 \%$ & 0.00 & Random \\
\hline Others & 5 & 0.79 & $0.58,1.08$ & 0.14 & $42.06 \%$ & 0.14 & Fixed \\
\hline Sputum & 6 & 1.30 & $1.04,1.60$ & 0.02 & $45.00 \%$ & 0.11 & Fixed \\
\hline Headache & 8 & 0.75 & $0.40,1.42$ & 0.38 & $49.57 \%$ & 0.06 & Random \\
\hline China & 5 & 0.68 & $0.24,1.95$ & 0.47 & $67.86 \%$ & 0.02 & Random \\
\hline China & 5 & 1.84 & $0.89,3.78$ & 0.10 & $92.85 \%$ & 0.00 & Random \\
\hline Others & 4 & 1.21 & $0.85,1.70$ & 0.30 & $0.00 \%$ & 0.67 & Fixed \\
\hline Diarrhoea & 8 & 0.68 & $0.39,1.19$ & 0.18 & $50.32 \%$ & 0.07 & Random \\
\hline China & 4 & 0.91 & $0.63,1.35$ & 0.66 & $8.01 \%$ & 0.35 & Fixed \\
\hline Others & 4 & 0.34 & $0.16,0.75$ & 0.01 & $39.66 \%$ & 0.17 & Fixed \\
\hline Haemoptisis & 5 & 1.40 & $0.66,2.97$ & 0.38 & $0.00 \%$ & 0.72 & Fixed \\
\hline Nausea/Vomiting & 7 & 0.83 & $0.52,1.34$ & 0.44 & $37.64 \%$ & 0.14 & Fixed \\
\hline Sore throat & 6 & 0.61 & $0.35,1.06$ & 0.08 & $0.00 \%$ & 0.92 & Fixed \\
\hline Dyspnoea & 7 & 1.88 & $1.16,3.03$ & 0.01 & $66.89 \%$ & 0.01 & Random \\
\hline China & 4 & 2.53 & $1.39,4.62$ & $<0.001$ & $73.42 \%$ & 0.02 & Random \\
\hline Others & 3 & 1.11 & $0.65,1.86$ & 0.72 & $0.00 \%$ & 0.83 & Fixed \\
\hline
\end{tabular}




$\begin{array}{lccccccc}\text { Others } & 12 & 2.32 & 1.60,3.39 & <0.001 & 90.48 \% & 0.02 & \text { Random } \\ \text { Hypertension } & 15 & 2.39 & 1.95,2.89 & <0.001 & 48.54 \% & 0.00 & \text { Random } \\ \quad \text { China } & 5 & 2.80 & 1.72,4.57 & <0.001 & 76.19 \% & 0.03 & \text { Random } \\ \quad \text { Others } & 10 & 2.27 & 1.77,2.94 & <0.001 & 48.20 \% & 0.02 & \text { Random } \\ \text { Malignancies } & 12 & 2.36 & 1.68,3.29 & <0.001 & 0.00 \% & 0.90 & \text { Fixed } \\ \text { COPD } & 11 & 1.99 & 1.51,2.64 & <0.001 & 30.06 \% & 0.16 & \text { Fixed } \\ \text { Cardiovascular disease } & 17 & 2.92 & 2.08,4.10 & <0.001 & 89.78 \% & 0.00 & \text { Random } \\ \quad \text { China } & 5 & 4.01 & 1.82,8.76 & <0.001 & 81.84 \% & 0.00 & \text { Random } \\ \quad \text { Others } & 12 & 2.66 & 1.79,3.97 & <0.001 & 91.60 \% & 0.00 & \text { Random } \\ \text { Cerebrovascular } & 10 & 2.69 & 2.01,3.60 & <0.001 & 20.37 \% & 0.26 & \text { Random } \\ \text { disease } & 15 & 3.03 & 1.77,5.16 & <0.001 & 80.83 \% & 0.00 & \text { Random } \\ \text { Chronic renal disease } & 5 & 1.75 & 0.98,3.13 & 0.06 & 36.58 \% & 0.18 & \text { Fixed } \\ \quad \text { China } & 10 & 3.46 & 1.80,6.69 & <0.001 & 85.39 \% & 0.00 & \text { Random } \\ \quad \text { Others } & 9 & 2.14 & 1.60,2.86 & <0.001 & 17.78 \% & 0.28 & \text { Fixed } \\ \text { Chronic liver disease } & 5 & 0.54 & 0.43,0.69 & <0.001 & 44.01 \% & 0.13 & \text { Fixed } \\ \text { Ground Glass Opacity } & 4 & 1.80 & 1.39,2.34 & <0.001 & 19.37 \% & 0.29 & \text { Fixed } \\ \text { Consolidation } & 4 & 16.44 & 6.23,43.82 & <0.001 & 82.67 \% & 0.00 & \text { Random } \\ \text { Acute cardiac injury } & 4 & 24.53 & 4.85,125.21 & <0.001 & 90.12 \% & 0.00 & \text { Random } \\ \text { Acute kidney injury } & 5 & 70.81 & 23.81,210.61 & <0.001 & 81.03 \% & 0.00 & \text { Random } \\ \text { ARDS } & 3 & 179.47 & 109.95,292.95 & <0.001 & 21.65 \% & 0.28 & \text { Random } \\ \quad \text { China } & 2 & 18.54 & 8.25,41.68 & <0.001 & 0.00 \% & 0.85 & \text { Fixed } \\ \quad \text { Others } & 3 & 28.50 & 5.93,135.64 & <0.001 & 0.00 \% & 0.65 & \text { Fixed } \\ \text { ECMO } & 6 & 11.25 & 1.80,70.11 & 0.01 & 89.92 \% & 0.00 & \text { Random } \\ \text { Noninvasive } & 3 & 64.07 & 14.44,284.29 & <0.001 & 83.15 \% & 0.03 & \text { Random } \\ \text { ventilation } & 3 & 1.63 & 0.43,6.23 & 0.47 & 0.00 \% & 0.78 & \text { Fixed } \\ \quad \text { China } & 6 & 24.29 & 5.53,106.70 & <0.001 & 91.36 \% & 0.00 & \text { Random } \\ \text { Others } & 3 & 81.45 & 46.06,144.03 & <0.001 & 0.00 \%, & 0.38 & \text { Fixed } \\ \text { Invasive mechanical } & 3 & 5.05 & 1.15,22.42 & 0.03 & 78.20 \% & 0.03 & \text { Random } \\ \text { ventilation } & & & & & & & \\ \quad \text { China } & & & & & \end{array}$

Table 3. Results of meta-analysis (continuous variable).

\begin{tabular}{|c|c|c|c|c|c|c|c|}
\hline \multirow{2}{*}{ Variable } & \multirow{2}{*}{ No. of Studies } & \multirow{2}{*}{ Mean Diff. } & \multirow{2}{*}{$95 \% \mathrm{CI}$} & \multirow{2}{*}{ P-Value } & \multicolumn{2}{|c|}{ Heterogeneity } & \multirow{2}{*}{ Model } \\
\hline & & & & & $\mathbf{I}^{2}$ & p & \\
\hline Age & 18 & 12.38 & $10.82,13.95$ & $<0.001$ & $87.27 \%$ & 0.00 & Random \\
\hline China & 7 & 13.18 & $9.94,16.42$ & $<0.001$ & $84.76 \%$ & 0.00 & Random \\
\hline Others & 11 & 12.20 & $10.46,13.93$ & $<0.001$ & $85.88 \%$ & 0.00 & Random \\
\hline haemoglobin & 9 & -1.40 & $-5.10,2.31$ & 0.46 & $86.81 \%$ & 0.00 & Random \\
\hline China & 3 & 1.16 & $-1.82,4.14$ & 0.45 & $61.92 \%$ & 0.06 & Random \\
\hline Others & 6 & -3.32 & $-8.83,2.18$ & 0.24 & $80.30 \%$ & 0.00 & Random \\
\hline platelet count & 9 & -35.30 & $-58.11,-12.50$ & $<0.001$ & $93.93 \%$ & 0.00 & Random \\
\hline China & 3 & -66.29 & $-102.31,-30.27$ & $<0.001$ & $93.41 \%$ & 0.00 & Random \\
\hline Others & 6 & -11.87 & $-16.02,-7.72$ & $<0.001$ & $0.00 \%$ & 0.89 & Fixed \\
\hline D-dimer & 12 & 5.39 & $1.32,9.46$ & 0.01 & $99.97 \%$ & 0.00 & Random \\
\hline China & 5 & 7.82 & $-0.88,16.53$ & 0.08 & $99.95 \%$ & 0.00 & Random \\
\hline Others & 7 & 3.60 & $0.19,7.02$ & 0.04 & $99.81 \%$ & 0.00 & Random \\
\hline prothrombin time & 6 & 1.32 & $0.42,2.21$ & $<0.001$ & $97.08 \%$ & 0.00 & Random \\
\hline APTT & 8 & 1.19 & $-0.34,2.72$ & 0.13 & $89.28 \%$ & 0.00 & Random \\
\hline China & 5 & 1.56 & $-0.58,3.70$ & 0.15 & $92.05 \%$ & 0.00 & Random \\
\hline Others & 3 & 0.56 & $-1.26,2.38$ & 0.55 & $63.63 \%$ & 0.06 & Random \\
\hline CRP & 13 & 63.81 & $38.14,89.49$ & $<0.001$ & $98.82 \%$ & 0.00 & Random \\
\hline China & 4 & 75.58 & $38.05,113.12$ & $<0.001$ & $98.36 \%$ & 0.00 & Random \\
\hline Others & 9 & 58.49 & $24.50,92.49$ & $<0.001$ & $98.55 \%$ & 0.00 & Random \\
\hline
\end{tabular}




\begin{tabular}{cccccccc} 
Procalcitonin & 7 & 0.64 & $0.22,1.06$ & $<0.001$ & $99.88 \%$ & 0.00 & Random \\
China & 3 & 0.26 & $0.11,0.41$ & $<0.001$ & $94.24 \%$ & 0.00 & Random \\
Others & 4 & 0.96 & $0.33,1.59$ & $<0.001$ & $95.41 \%$ & 0.00 & Random \\
Interleukin 6 & 5 & 171.45 & $66.37,276.53$ & $<0.001$ & $99.47 \%$ & 0.00 & Random \\
China & 3 & 209.35 & $43.43,375.26$ & 0.01 & $99.46 \%$ & 0.00 & Random \\
Others & 2 & 119.2 & $-4.08,242.48$ & 0.06 & $99.28 \%$ & 0.00 & Random \\
\hline
\end{tabular}

heterogeneity was not significant $\left(\mathrm{I}^{2}<50 \%\right.$ and $P>0.1$ in the $\mathrm{Q}$ test), the fixed-effects model was used. However, we employed the random-effects model for the analyses of fever, cough, headache, and diarrhea because the heterogeneity was significant $\left(\mathrm{I}^{2} \geq 50 \%\right.$ or $P<0.1$ in the Q test) (Table 2 and Supplementary Figure 1).

\section{Comorbidities}

We conducted a systematic analysis of the difference in the prevalence of comorbidities between death and survival cases. The heterogeneity test showed high heterogeneity of diabetes, hypertension, cardiovascular disease, cerebrovascular disease, and chronic renal disease, and the random-effects model was used for the meta-analysis. However, we used the fixed-effects model for malignancies, chronic obstructive pulmonary disease (COPD), and chronic liver disease because the heterogeneity levels were not significant $\left(\mathrm{I}^{2}<50 \%\right.$ and $P>0.1$ in the $\mathrm{Q}$ test) (Table 2). The death group had significantly higher proportions of patients with diabetes $(\mathrm{OR}=2.51,95 \%$ CI: $1.86-3.35, \quad P<0.001)$, hypertension $(\mathrm{OR}=2.39$, 95\% CI: $1.95-2.89, P<0.001)$, cardiovascular disease $(\mathrm{OR}=2.92,95 \%$ CI: 2.08-4.10, $P<0.001)$, chronic renal disease (OR=3.03, 95\% CI: 1.77-5.16, $P<0.001)$, malignancies $\quad(\mathrm{OR}=2.36, \quad 95 \% \quad \mathrm{CI}: \quad 1.68-3.29$, $P<0.001)$, COPD (OR=1.99, 95\% CI: 1.51-2.64, $P<0.001)$, cerebrovascular disease $(\mathrm{OR}=2.69,95 \% \mathrm{CI}$ : 2.01-3.60, $P<0.001$ ), and chronic liver disease $(\mathrm{OR}=2.14,95 \%$ CI: $1.60-2.86, P<0.001)$ than the survival group (Table 2 and Supplementary Figure 1).

\section{Laboratory examinations}

The heterogeneity levels were high in the analyses of hemoglobin, platelet count, D-dimer, prothrombin time (PT), activated partial thromboplastin time (APTT), Creactive protein (CRP), procalcitonin, and interleukin 6 (IL6) (Table 3). The results showed that death cases displayed a statistically significant lower platelet count than survival cases $(\mathrm{MD}=-35.3,95 \% \mathrm{CI}$ : $[-58.11,-12.50]$, $P<0.001)$. Moreover, the pooled results of these studies revealed that the death group had significantly higher levels of D-dimer (MD $=5.39 \mu \mathrm{g} / \mathrm{mL}, 95 \% \mathrm{CI}$ : $1.32,9.46$; $P=0.01$ ), prothrombin time (MD=1.32 s, 95\% CI: $0.42-$ 2.21, $P<0.001$ ), CRP (MD=63.81 mg/L, 95\% CI: 38.1489.49, $P<0.001)$, procalcitonin $(\mathrm{MD}=0.64 \mathrm{ng} / \mathrm{mL}, 95 \%$
CI: 0.22-1.06, $P<0.001$ ), and interleukin 6 (MD=171.45 $\mathrm{pg} / \mathrm{mL}, 95 \%$ CI: $66.37-276.53, P<0.001)$ than the survival group. However, the former group had higher APTT than the latter group $(\mathrm{MD}=1.19 \mathrm{~s}, 95 \% \mathrm{CI}:[-0.34,2.72]$, $P=0.13$ ), and the differences in the APTT and hemoglobin levels between the two groups were not statistically significant (Table 3 and Supplementary Figure 1).

\section{Imaging features}

The analysis of imaging examinations is shown in Table 2. Consolidation was more likely to occur in the death group $(\mathrm{OR}=1.80,95 \% \mathrm{CI}: 1.39-2.34, P<0.001)$. The fixed effect-model for the Ground Glass Opacity $\left(\mathrm{I}^{2}=\right.$ $44.01 \%, P=0.13$ ) showed that the consolidation was lower in the death group (OR $=0.54,95 \%$ CI: 0.43-0.69, $P<0.001$ ) (Table 2 and Supplementary Figure 1).

\section{Complications and supportive treatment}

The random-effects model was used for acute cardiac injury, acute kidney injury, Acute Respiratory Distress Syndrome (ARDS), noninvasive ventilation and invasive mechanical ventilation because the heterogeneity was significant $\left(\mathrm{I}^{2} \geq 50 \%\right.$ or $P<0.1$ in the $\mathrm{Q}$ test). Meanwhile, we used the fixed-effects model for extracorporeal membrane oxygenation (ECMO) as no heterogeneity was observed $\left(\mathrm{I}^{2}=0 \%, P=0.65\right)$. The metaanalysis showed that the death group had significantly higher proportions of patients with acute cardiac injury (OR=16.44, 95\% CI: 6.23-43.82, $P<0.001)$, ARDS (OR=70.81, 95\% CI: 23.81-210.61, $P<0.001)$, and acute kidney injury $(\mathrm{OR}=24.53,95 \% \quad \mathrm{CI}: 4.85-125.21$, $P<0.001)$ than the survival group. All of the supportive treatment options were more frequently used in the death group than in the survival group (ECMO: $\mathrm{OR}=28.50,95 \%$ CI: 5.93-135.64, $P<0.001$; noninvasive ventilation: $\mathrm{OR}=11.25,95 \% \mathrm{CI}: 1.80-70.11, P=0.01$; and invasive mechanical ventilation: $\mathrm{OR}=24.29,95 \%$ CI: 5.53-106.70, $P<0.001$ ) (Table 2 and Supplementary Figure 1).

\section{Subgroup analysis}

Some meta-analysis results have high levels of heterogeneity. To further verify the correlation between clinical indicators and the prognosis of COVID-19 patients, subgroup analysis was performed by region. 
Table 4. Results of trim and fill method and publication bias (binary variable).

\begin{tabular}{lccccc}
\hline \multirow{2}{*}{ Variable } & \multirow{2}{*}{ No. of Studies } & \multirow{2}{*}{ OR(95\% CI) } & Observed + Imputed & \multirow{2}{*}{ P-Value } & \multirow{2}{*}{ Method } \\
& & $0.84(0.57,1.21)$ & $1.03(0.71,1.49)$ & 0.18 & Harbord \\
Fever & 11 & $0.87(0.56,1.35)$ & $0.87(0.56,1.35)$ & 0.90 & Harbord \\
Cough & 12 & $2.51(1.86,3.35)$ & $2.51(1.86,3.35)$ & 0.35 & Harbord \\
Diabetes & 18 & $2.39(1.95,2.89)$ & $2.39(1.95,2.89)$ & 0.32 & Harbord \\
Hypertension & 15 & $2.36(1.68,3.29)$ & $2.24(1.61,3.12)$ & 0.85 & Harbord \\
Malignancies & 12 & $1.99(1.51,2.64)$ & $1.95(1.47,2.58)$ & 0.18 & Harbord \\
COPD & 11 & $2.92(2.08,4.10)$ & $2.92(2.08,4.10)$ & 0.29 & Harbord \\
Cardiovascular disease & 17 & $2.69(2.01,3.60)$ & $2.44(1.85,3.21)$ & 0.01 & Harbord \\
Cerebrovascular disease & 10 & $3.03(1.77,5.16)$ & $3.03(1.77,5.16)$ & 0.83 & Harbord \\
Chronic renal disease & 15 & & & & \\
\hline
\end{tabular}

Table 5. Results of trim and fill method and publication bias (continuous variable).

\begin{tabular}{lcccccc}
\hline \multirow{2}{*}{ Variable } & \multirow{2}{*}{ No. of Studies } & \multirow{2}{*}{ Mean Diff.(95\% CI) } & Observed + Imputed & \multirow{2}{*}{ P-Value } & \multirow{2}{*}{ Method } \\
\cline { 4 - 6 } Age & 18 & $12.38(10.82,13.95)$ & $12.38(10.82,13.95)$ & 0.70 & Egger \\
D-dimer & 12 & $5.39(1.32,9.46)$ & $5.39(1.32,9.46)$ & 0.00 & Egger \\
CRP & 13 & $63.81(38.14,89.49)$ & $63.81(38.14,89.49)$ & 0.86 & Egger \\
\hline
\end{tabular}

China is the country where the first outbreak occurred while some other countries reported cases later. The results of the subgroup analysis are presented in Tables 2,3 .

\section{Publication bias}

According to the number of studies $(n \geq 10)$, the risk of publication bias was analyzed in the following variables: gender, age, fever, cough, diabetes, hypertension, COPD, malignancies, cardiovascular disease, cerebrovascular disease, chronic renal disease, D-dimer, and CRP. The publication bias in meta-analyses of continuous (or nonbinary) variables was evaluated using the Egger's regression test while the Harbord test was used for binary variables. All $P$-values of $>0.05$ suggest no significant publication bias. In addition, we addressed the potential publication bias by the trim-and-fill method. The OR values and $95 \%$ CIs before and after the application of the method are shown in Tables 4 and 5, and the funnel plots for eliminating the publication offset are presented in Figure 2.

\section{DISCUSSION}

Since December 2019, SARS-CoV-2 infection has been spreading worldwide, and a large number of confirmed cases have died from COVID-19. The current rapid spread of this infection is an emergency that primarily threatens the preparedness and biosecurity conditions of all affected countries [30]. According to previous research analyzing the cause of death of COVID-19- infected patients in Wuhan University Zhong Nan Hospital, $58.8 \%, 23.5 \%, 11.8 \%$, and $5.9 \%$ of patients died owing to multiple organ dysfunction syndrome, cardiac arrest, respiratory failure, and acute respiratory distress syndrome, respectively [11]. The severity and outcome of COVID-19 largely depend on a patient's age. Viable hypotheses are emerging that also include changes to the immune cell repertoire, epigenome, NAD+ levels, inflammasome activity, biological clocks, and covalent modifications of human and viral proteins [31]. Unfortunately, the knowledge regarding SARSCoV-2 remains limited. Antiviral therapies and vaccinations are currently under development, and their effectiveness is under evaluation [32]. As the mortality rate of COVID-19 is increasing rapidly, it is of great importance to determine the general condition of infected patients and reduce the mortality rate by taking advantage of existing treatment options.

Our meta-analysis of 19 studies provides a comprehensive comparison of clinical symptoms, comorbidities, laboratory findings, chest imaging findings, complications, and supportive treatment between mortal patients and survivors. This study is expected to assist clinicians in identifying some alarming clinical characteristics presented by patients at an early stage to prevent mortality and provide instructions on the appropriate and effective management of future infections.

Many patients have been indicated to undergo nucleic acid tests on the onset of COVID-19-related symptoms. 
The period between the onset of symptoms and death ranged from 6 to 41 days, with a median of 14 days [33]. The most common COVID-19 symptoms at infection onset include fever, cough, and fatigue, while other symptoms are sore throat, sputum, headache, myalgia, anorexia, hemoptysis, diarrhea, and dyspnea [4, 33-35]. Notably, the transmission of SARS-COV-2 occurs during the prodromal period when infected individuals are mildly ill and undertake routine activities, contributing to the spread of infection. This indicated that a large number of asymptomatic carriers remain undiscovered [36]. It is crucial to identify and isolate asymptomatic carriers to contain outbreaks in later stages. At the same time, a prognosis should be made as soon as people present with mild symptoms to choose appropriate treatment options. Our data analysis showed that sputum, fatigue, and dyspnea occurred more significantly in mortal cases. However, the difference was not significant with other symptoms, such as fever, cough, headache, myalgia, diarrhea, hemoptysis, nausea/vomiting, and sore throat. Because of low specificity of clinical symptoms and the presence of various systemic symptoms, determining prognosis based on initial symptoms is not recommended.
A

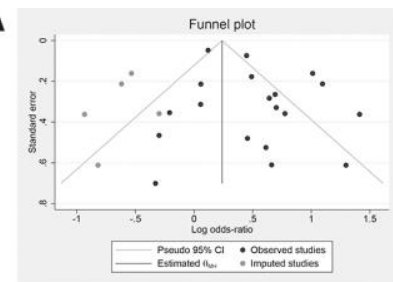

Gender-male

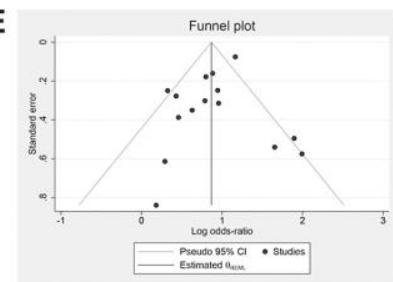

Hypertension

I

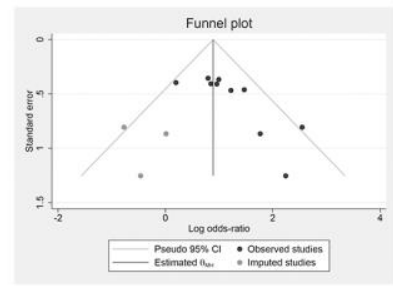

Cerebrovascular disease

M

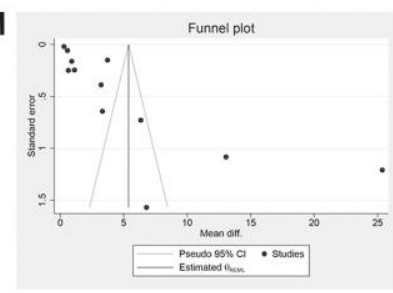

D-dimer
B

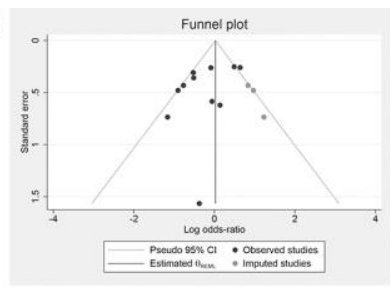

Fever

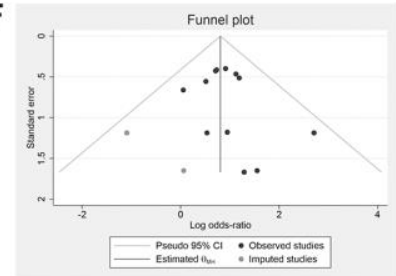

Malignancies

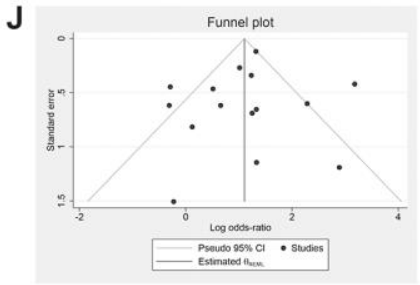

Chronic renal disease
C

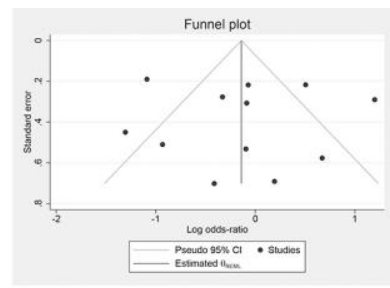

Cough

G

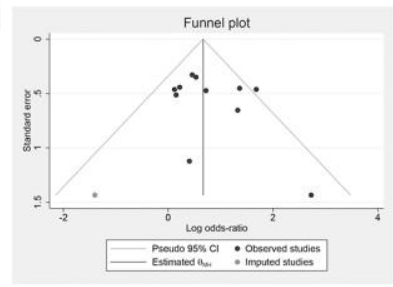

COPD

K

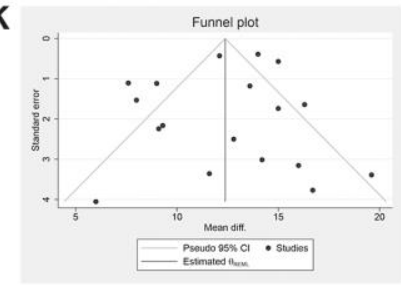

Age
D

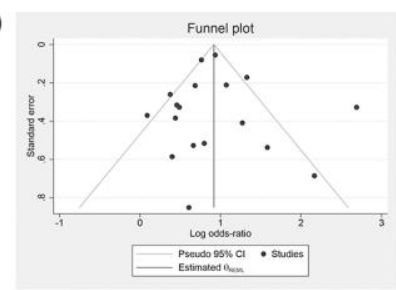

Diabetes

H

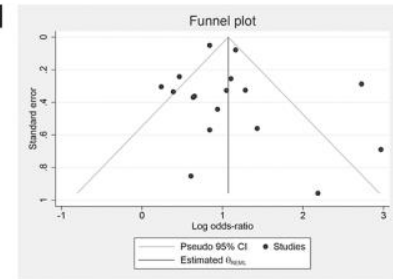

Cardiovascular disease

L

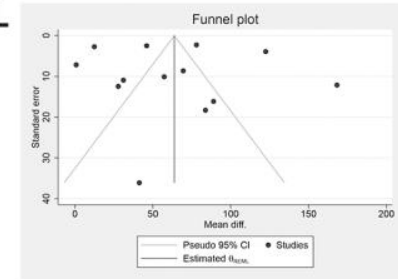

CRP

Figure 2. Results of publication bias and trim and fill method. (A) Gender-male; (B) Fever; (C) Cough; (D) Diabetes; (E) Hypertension; (F) Malignancies; (G) COPD; (H) Cardiovascular disease; (I) Cerebrovascular disease; (J) Chronic renal disease; (K) Age; (L) CRP; (M) D-dimer. 
According to previous studies, circulatory and endocrine comorbidities were commonly found in COVID-19 patients. Having at least one comorbidity was associated with a poor clinical outcome. Comorbidities such as chronic obstructive pulmonary disease (COPD), diabetes, hypertension, and malignancy predisposed COVID-19 patients to adverse clinical outcomes, similar to those infected with SARS$\mathrm{CoV}$ and MERS-CoV, which caused severe acute respiratory syndromes. [37-41]. It is worth noting that some comorbidities frequently co-exist with each other. For instance, diabetes [42] and COPD [43] are often comorbid with hypertension or coronary heart diseases. Patients with co-existing comorbidities are more likely to have worse baseline health status; hence, it is necessary to comprehensively consider the prognostic impact of COVID-19 in patients with comorbidities. In our meta-analysis, we identified an increased risk of mortality in patients with confirmed COVID-19 who also had hypertension, diabetes, COPD, malignancies, cardiovascular disease, chronic renal disease, chronic liver disease, or cerebrovascular disease. Cardiovascular and cerebrovascular diseases were more likely to occur in middle-aged and older adults, and the mean age of the patients in the 19 included studies was more than 46 years. The physical health status of those with these levels in patients with COVID-19 [45-47]. However, physicians cannot rely on these non-specific laboratory markers to exclude or confirm the diagnosis of COVID19. Instead, the prognosis can be predicted using laboratory indicators. Our present study focused on coagulation as an indicator of infected patients. The results showed that platelet count in the mortal group was significantly lower than that in the survival group, and coagulation indicators, i.e., D-dimer and PT, in the former group were significantly higher than that in the latter group. This suggested that COVID-19 patients are more likely to develop coagulation disorders, for example, disseminated intravascular coagulation (DIC). In particular, the increase in the fibrin degradation product D-dimer, released from blood clots in the microvasculature, is a prognostic marker for DIC [48]. Furthermore, the relevance of thrombocytopenia in patients with DIC is associated with the risk of bleeding. Previous studies showed that $50 \%-60 \%$ of DIC patients had a platelet count of $<100 \times 10^{9} / \mathrm{L}$, whereas $10 \%-15 \%$ of patients had a platelet count of $<50 \times 10^{9} / \mathrm{L}$. In addition, the level of coagulation factors appears to correlate well with the severity of DIC. The low level of coagulation factors is reflected by prolonged coagulation screening tests, such as PT or APTT. A prolonged PT or APTT occurs in $14 \%-28 \%$ of intensive care patients but is present in more than 95\% of patients with DIC [49-52]. Moreover, viral infections could cause inflammation in the body, and the increased inflammatory factors would lead to systemic immune damage and ultimately organ comorbidities was relatively poor, thereby affecting prognosis. Furthermore, studies have indicated that ACE2 gene expression could explain why cardiovascular disease- and hypertension-predisposed patients develop a more aggressive form of COVID-19, and it is related to age, which is consistent with our analysis [44]. Patients with COPD had poor prognosis of COVID-19 because SARS-CoV-2 infection inevitably aggravated existing symptoms. In patients with chronic liver diseases, kidney diseases, or malignancies, homeostatic imbalance would further impair the functions of multiple systems after SARSCoV-2 infection. To analyze results with high heterogeneity, we conducted country-specific subgroup analysis. This analysis supported that comorbidities such as hypertension, diabetes, COPD, malignancies, cardiovascular disease, chronic renal disease, chronic liver disease, and cerebrovascular disease were risk factors for COVID-19-related mortality. Therefore, both the category and number of comorbidities should be considered when determining the prognosis in patients with COVID-19.

Previous studies have reported laboratory examination abnormalities such as reduced lymphocyte count and elevated C-reactive protein and lactate dehydrogenase failure. Furthermore, hyperactivation of the immune system could cause a "cytokine storm," which exacerbates dyspnea and hypoxemia and triggers inflammation in major tissues such as the lungs, kidneys, heart, liver, and brain. [53]. Therefore, the early detection of inflammatory indicators is integral, which was also verified in our analysis. Inflammatory indicators (i.e., CRP, procalcitonin, and IL6) in the mortal group were significantly higher than those in the survival group, showing that they can be used as prognostic clinical indicators. Our meta-analysis was limited owing to regional variation across the included studies; nevertheless, we, to a certain extent, minimized this bias through subgroup analysis.

In addition to laboratory indicators, imaging features are helpful for diagnosis and prognosis. Imaging features of viral infections usually appear as multifocal groundglass opacities. According to a previous study, groundglass opacities on CT corresponded to pathological diffuse alveolar damage [52]. Another study indicated that common CT imaging features in patients with COVID-19 pneumonia were bilateral and had multifocal ground-glass opacities with peripheral distribution [54]. In our meta-analysis, we found that consolidation was closely related to mortality.

According to our results, organ failure is more likely to occur in patients with poor prognosis. Therefore, monitoring the cardiopulmonary function of ICU or 
critical patients is highly recommended. Regarding supportive treatment of COVID-19 patients, mechanical ventilation is the most widely used short-term life support technique worldwide, and it is used on a daily basis for a diverse spectrum of indications, from scheduled surgical procedures to acute organ failure [55]. Our analysis also revealed that during the COVID19 pandemic, mechanical ventilation and extracorporeal membrane oxygenation (ECMO) play a crucial role in the treatment of critical and fatal cases. However, a ventilator may lead to subsequent infections as bacteria can invade the lungs via the tracheostomy tube. Other problems include lung damage, pneumothorax, and an inability to discontinue ventilator support [56]. With an increasing number of patients with severe symptoms, a method for rationally and safely using mechanical ventilation needs to be urgently developed.

\section{Study limitations}

Our current study has several limitations, namely the small number of reviewed studies, and limited data availability. The main drawback of this meta-analysis is the heterogeneity of included cases. The patients in different studies might be at different stages of disease. Furthermore, differences in the duration of observation for each study, as well as differences in treatment styles and levels across regions and hospitals, might contribute to heterogeneity. Considering the current global epidemic of COVID-19, future analysis should include more international publications. Our research will be updated when new evidence emerges.

\section{MATERIALS AND METHODS}

\section{Search strategy}

Our current meta-analysis was reported in accordance with the Preferred Reporting Items for Systematic Reviews and Meta-Analyses (PRISMA) Statement. We selected relevant studies published between Jan 1, 2020 and Aug 10, 2020, by searching them in PubMed, Embase, and CNKI, regardless of language of publication. The terms for the literature search were combinations of "severe acute respiratory syndrome coronavirus 2", "SARS-CoV-2,2019 novel coronavirus", "COVID-19", "2019-nCoV", "Novel coronavirus 2019", with "fatality", "death", "nonsurvivor", "mortality", "fetal", and "dead". In conformity with the quality standards for reporting systematic reviews and meta-analyses of observational studies, two independent researchers (Zhou XH and Cheng ZP) screened retrieved articles. The researchers independently assessed full texts of articles deemed eligible for inclusion. All disagreements were resolved by discussion with a third reviewer $(\mathrm{Hu} \mathrm{Yu})$.

\section{Selection criteria}

The inclusion criteria were as follows: (1) patients should be confirmed to have been infected with SARSCoV-2; (2) each study should consist of a death group; (3) the full text of each article should be available; and (4) at least one outcome was reported among demographical characteristics, comorbidities, clinical characteristics, laboratory examinations, or image examinations. Meanwhile, duplicate reports, clinical guidelines, consensus documents, reviews, and systematic reviews were excluded from our metaanalysis.

\section{Data analysis}

Two authors (Zhou XH and Cheng ZP) independently extracted relevant information, including first author, published journal, publication time, country, the number of COVID-19 patients, the mean or median age of patients, gender ratio, the presence of clinical symptoms, comorbidities, laboratory findings, image examinations, complications, and supportive treatment. All data analyses were performed using STATA 16.0 software. The ORs, mean differences, and relevant 95\% CIs were used to estimate pooled results from studies. In case of no obvious heterogeneity $\left(\mathrm{I}^{2}<50 \%\right.$ and $P>0.1$ in the Q test), the fixed-effects model was applied. Otherwise, the random-effects model was used. All $P$ values of $\leq 0.05$ were considered to be significant statistically. When the analysis included no less than ten articles, we performed the Egger's regression test and the Harbord test to analyze the publication bias. Furthermore, we used the trim-and-fill method to eliminate the impact of the publication bias.

\section{Editorial note}

${ }^{\&}$ This corresponding author has a verified history of publications using a personal email address for correspondence.

\section{AUTHOR CONTRIBUTIONS}

Xianghui Zhou made the design of the work; Xianghui Zhou, Zhipeng Cheng, Dan Shu, Wenyi Lin, Zhangyin Ming searched, selected materials and extracted data; Xianghui Zhou and Zhipeng Cheng wrote this manuscript; $\mathrm{Yu} \mathrm{Hu}$ and Wei Chen revised the paper carefully. All authors have read and approved the final manuscript.

\section{CONFLICTS OF INTEREST}

The authors declare to have no conflicts of interest. 


\section{FUNDING}

This study was supported by grant from the National Natural Science Foundation of China (81800134 to Cheng Zhipeng), grant from the Key Special Project of Ministry of Science and Technology, China (No.2020YFC0845700 to $\mathrm{Hu} \mathrm{Yu}$ ) and grant from Scientific Research Projects of Chinese Academy of Engineering (NO.2020-KYGG-01-07 to Chen Wei).

\section{REFERENCES}

1. Lu H, Stratton CW, Tang YW. Outbreak of pneumonia of unknown etiology in Wuhan, China: the mystery and the miracle. J Med Virol. 2020; 92:401-02. https://doi.org/10.1002/imv.25678 PMID:31950516

2. Zhu N, Zhang D, Wang W, Li X, Yang B, Song J, Zhao X, Huang B, Shi W, Lu R, Niu P, Zhan F, Ma X, et al, and China Novel Coronavirus Investigating and Research Team. A novel coronavirus from patients with pneumonia in China, 2019. N Engl J Med. 2020; 382:727-33.

https://doi.org/10.1056/NEJMoa2001017 PMID:31978945

3. Lu R, Zhao X, Li J, Niu P, Yang B, Wu H, Wang W, Song $\mathrm{H}$, Huang B, Zhu N, Bi Y, Ma X, Zhan F, et al. Genomic characterisation and epidemiology of 2019 novel coronavirus: implications for virus origins and receptor binding. Lancet. 2020; 395:565-74.

https://doi.org/10.1016/S0140-6736(20)30251-8 PMID: $\underline{32007145}$

4. Huang $C$, Wang $Y$, Li X, Ren L, Zhao J, Hu Y, Zhang L, Fan G, Xu J, Gu X, Cheng Z, Yu T, Xia J, et al. Clinical features of patients infected with 2019 novel coronavirus in Wuhan, China. Lancet. 2020; 395:497-506. https://doi.org/10.1016/S0140-6736(20)30183-5 PMID:31986264

5. Biscayart C, Angeleri P, Lloveras S, Chaves TDSS, Schlagenhauf $P$, Rodríguez-Morales AJ. The next big threat to global health? 2019 novel coronavirus (2019$\mathrm{nCoV})$ : What advice can we give to travellers? - Interim recommendations January 2020, from the LatinAmerican society for Travel Medicine (SLAMVI). Travel Med Infect Dis. 2020; 33:101567.

https://doi.org/10.1016/i.tmaid.2020.101567 PMID:32006657

6. Guan WJ, Ni ZY, Hu Y, Liang WH, Ou CQ, He JX, Liu L, Shan $H$, Lei CL, Hui DS, Du B, Li LJ, Zeng G, et al, and China Medical Treatment Expert Group for Covid-19. Clinical characteristics of coronavirus disease 2019 in China. N Engl J Med. 2020; 382:1708-20. https://doi.org/10.1056/NEJMoa2002032 PMID:32109013
7. Chen $G$, Wu D, Guo W, Cao Y, Huang D, Wang H, Wang $T$, Zhang $X$, Chen $H, Y u H$, Zhang $X$, Zhang $M$, Wu S, et al. Clinical and immunological features of severe and moderate coronavirus disease 2019. J Clin Invest. 2020; 130:2620-29.

https://doi.org/10.1172/JCl137244 PMID:32217835

8. Long $\mathrm{C}, \mathrm{Xu} \mathrm{H}$, Shen $\mathrm{Q}$, Zhang $\mathrm{X}$, Fan B, Wang C, Zeng B, Li Z, Li X, Li H. Diagnosis of the coronavirus disease (COVID-19): rRT-PCR or CT? Eur J Radiol. 2020; 126:108961.

https://doi.org/10.1016/i.ejrad.2020.108961 PMID:32229322

9. Yuan $M$, Yin W, Tao Z, Tan W, Hu Y. Association of radiologic findings with mortality of patients infected with 2019 novel coronavirus in Wuhan, China. PLoS One. 2020; 15:e0230548.

https://doi.org/10.1371/journal.pone.0230548 PMID:32191764

10. Zhai $P$, Ding $Y, W u X$, Long J, Zhong $Y$, Li $Y$. The epidemiology, diagnosis and treatment of COVID-19. Int J Antimicrob Agents. 2020; 55:105955. https://doi.org/10.1016/j.ijantimicag.2020.105955 PMID:32234468

11. Cao J, Tu WJ, Cheng W, Yu L, Liu YK, Hu X, Liu Q. Clinical Features and Short-term Outcomes of 102 Patients with Coronavirus Disease 2019 in Wuhan, China. Clin Infect Dis. 2020; 71:748-755.

https://doi.org/10.1093/cid/ciaa243 PMID:32239127

12. Du RH, Liang LR, Yang CQ, Wang W, Cao TZ, Li M, Guo GY, Du J, Zheng CL, Zhu Q, Hu M, Li XY, Peng P, Shi HZ. Predictors of mortality for patients with COVID-19 pneumonia caused by SARS-CoV-2: a prospective cohort study. Eur Respir J. 2020; 55:2000524. https://doi.org/10.1183/13993003.00524-2020 PMID: $\underline{2269088}$

13. Wang L, He W, Yu X, Hu D, Bao M, Liu H, Zhou J, Jiang H. Coronavirus disease 2019 in elderly patients: characteristics and prognostic factors based on 4-week follow-up. J Infect. 2020; 80:639-45. https://doi.org/10.1016/i.jinf.2020.03.019 PMID: $\underline{2240670}$

14. Javanian $M$, Bayani $M$, Shokri $M$, Sadeghi-HaddadZavareh M, Babazadeh A, Yeganeh B, Mohseni S, Mehraeen R, Sepidarkish M, Bijani A, Rostami A, Shahbazi M, Tabari AM, et al. Clinical and laboratory findings from patients with COVID-19 pneumonia in babol north of Iran: a retrospective cohort study. Rom J Intern Med. 2020; 58:161-67. https://doi.org/10.2478/riim-2020-0013 PMID: $\underline{32396143}$

15. Li Q, Cao Y, Chen L, Wu D, Yu J, Wang H, He W, Chen L, Dong $F$, Chen $W$, Chen $W$, Li L, Ran $Q$, et al. 
Hematological features of persons with COVID-19. Leukemia. 2020; 34:2163-2172.

https://doi.org/10.1038/s41375-020-0910-1

PMID:32528042

16. Okoh AK, Sossou C, Dangayach NS, Meledathu S, Phillips O, Raczek C, Patti M, Kang N, Hirji SA, Cathcart C, Engell C, Cohen M, Nagarakanti S, et al. Coronavirus disease 19 in minority populations of Newark, New Jersey. Int J Equity Health. 2020; 19:93. https://doi.org/10.1186/s12939-020-01208-1 PMID:32522191

17. Rath $D$, Petersen-Uribe Á, Avdiu A, Witzel K, Jaeger $P$, Zdanyte M, Heinzmann D, Tavlaki E, Müller K, Gawaz MP. Impaired cardiac function is associated with mortality in patients with acute COVID-19 infection. Clin Res Cardiol. 2020. [Epub ahead of print]. https://doi.org/10.1007/s00392-020-01683-0 PMID:32537662

18. Khalil K, Agbontaen K, McNally D, Love A, Mandalia $S$, Banya W, Starren E, Dhunnookchand R, Farne $H$, Morton R, Davies G, Orhan O, Lai D, et al. Clinical characteristics and 28-day mortality of medical patients admitted with COVID-19 to a central London teaching hospital. J Infect. 2020; 81:e85-89. https://doi.org/10.1016/i.jinf.2020.06.027 PMID:32562795

19. Nowak B, Szymański P, Pańkowski I, Szarowska A, Życińska K, Rogowski W, Gil R, Furmanek M, Tatur J, Zaczyński A, Król Z, Wierzba W. Clinical characteristics and short-term outcomes of patients with coronavirus disease 2019: a retrospective single-center experience of a designated hospital in Poland. Pol Arch Intern Med. 2020; 130:407-11.

https://doi.org/10.20452/pamw.15361

PMID:32420710

20. Shahriarirad R, Khodamoradi Z, Erfani A, Hosseinpour H, Ranjbar K, Emami Y, Mirahmadizadeh A, Lotfi M, Shirazi Yeganeh B, Dorrani Nejad A, Hemmati A, Ebrahimi M, Moghadami M. Epidemiological and clinical features of 2019 novel coronavirus diseases (COVID-19) in the South of Iran. BMC Infect Dis. 2020; 20:427.

https://doi.org/10.1186/s12879-020-05128-x PMID:32552751

21. Wang $K$, Zuo $P$, Liu $Y$, Zhang $M$, Zhao $X$, Xie $S$, Zhang $H$, Chen X, Liu C. Clinical and laboratory predictors of in-hospital mortality in patients with COVID-19: a cohort study in Wuhan, China. Clin Infect Dis. 2020. 71:2079-88.

https://doi.org/10.1093/cid/ciaa538 PMID:32361723

22. Aloisio E, Chibireva M, Serafini L, Pasqualetti S, Falvella FS, Dolci A, Panteghini M. A comprehensive appraisal of laboratory biochemistry tests as major predictors of
COVID-19 severity. Arch Pathol Lab Med. 2020. [Epub ahead of print]. https://doi.org/10.5858/arpa.2020-0389-SA PMID:32649222

23. Baqui P, Bica I, Marra V, Ercole A, van der Schaar M. Ethnic and regional variations in hospital mortality from COVID-19 in Brazil: a cross-sectional observational study. Lancet Glob Health. 2020; 8:e1018-26. https://doi.org/10.1016/S2214-109X(20)30285-0 PMID:32622400

24. Berenguer J, Ryan $P$, Rodríguez-Baño J, Jarrín I, Carratalà J, Pachón J, Yllescas M, Arribas JR, and COVID-19@Spain Study Group. Characteristics and predictors of death among 4,035 consecutively hospitalized patients with COVID-19 in Spain. Clin Microbiol Infect. 2020; S1198-743X:30431-36. https://doi.org/10.1016/i.cmi.2020.07.024 PMID:32758659

25. Bonetti G, Manelli F, Patroni A, Bettinardi A, Borrelli G, Fiordalisi G, Marino A, Menolfi A, Saggini S, Volpi R, Anesi A, Lippi G. Laboratory predictors of death from coronavirus disease 2019 (COVID-19) in the area of Valcamonica, Italy. Clin Chem Lab Med. 2020; 58:1100-05.

https://doi.org/10.1515/cclm-2020-0459 PMID:32573995

26. Gayam V, Chobufo MD, Merghani MA, Lamichhane S, Garlapati PR, Adler MK. Clinical characteristics and predictors of mortality in African-Americans with COVID-19 from an inner-city community teaching hospital in New York. J Med Virol. 2020; 10:1002. https://doi.org/10.1002/jmv.26306 PMID:32672844

27. Liu J, Zhang $S, W u Z$, Shang $Y$, Dong $X$, Li G, Zhang L, Chen $Y$, Ye X, Du H, Liu Y, Wang T, Huang S, et al. Clinical outcomes of COVID-19 in Wuhan, China: a large cohort study. Ann Intensive Care. 2020; 10:99. https://doi.org/10.1186/s13613-020-00706-3 PMID: 32737627

28. Salacup G, Lo KB, Gul F, Peterson E, De Joy R, Bhargav $\mathrm{R}$, Pelayo J, Albano J, Azmaiparashvili Z, Benzaquen S, Patarroyo-Aponte G, Rangaswami J. Characteristics and clinical outcomes of COVID-19 patients in an underserved-inner city population: A single tertiary center cohort. J Med Virol. 2020. [Epub ahead of print]. https://doi.org/10.1002/jmv.26252 PMID: $\underline{32617986}$

29. Yu C, Lei Q, Li W, Wang X, Liu W, Fan X, Li W. Clinical characteristics, associated factors, and predicting COVID-19 mortality risk: a retrospective study in Wuhan, China. Am J Prev Med. 2020; 59:168-75. https://doi.org/10.1016/i.amepre.2020.05.002 PMID:32564974 
30. Wu F, Zhao S, Yu B, Chen YM, Wang W, Song ZG, Hu Y, Tao ZW, Tian JH, Pei YY, Yuan ML, Zhang YL, Dai FH, et al. A new coronavirus associated with human respiratory disease in China. Nature. 2020; 579:265-69. https://doi.org/10.1038/s41586-020-2008-3

PMID:32015508

31. Mueller AL, McNamara MS, Sinclair DA. Why does COVID-19 disproportionately affect older people? Aging (Albany NY). 2020; 12:9959-81.

https://doi.org/10.18632/aging.103344

PMID: $\underline{32470948}$

32. Lai CC, Shih TP, Ko WC, Tang HJ, Hsueh PR. Severe acute respiratory syndrome coronavirus 2 (SARS-CoV2) and coronavirus disease-2019 (COVID-19): the epidemic and the challenges. Int J Antimicrob Agents. 2020; 55:105924.

https://doi.org/10.1016/j.ijantimicag.2020.105924 PMID:32081636

33. Wang W, Tang J, Wei F. Updated understanding of the outbreak of 2019 novel coronavirus (2019-nCoV) in Wuhan, China. J Med Virol. 2020; 92:441-47.

https://doi.org/10.1002/jmv.25689

PMID: $\underline{1994742}$

34. Carlos WG, Dela Cruz CS, Cao B, Pasnick S, Jamil S. Novel Wuhan (2019-nCoV) coronavirus. Am J Respir Crit Care Med. 2020; 201:P7-P8.

https://doi.org/10.1164/rccm.2014P7 PMID:32004066

35. Ren LL, Wang YM, Wu ZQ, Xiang ZC, Guo L, Xu T, Jiang YZ, Xiong Y, Li YJ, Li XW, Li H, Fan GH, Gu XY, et al. Identification of a novel coronavirus causing severe pneumonia in human: a descriptive study. Chin Med J (Engl). 2020; 133:1015-24. https://doi.org/10.1097/CM9.0000000000000722 PMID:32004165

36. Heymann DL, Shindo N, and WHO Scientific and Technical Advisory Group for Infectious Hazards. COVID-19: what is next for public health? Lancet. 2020; 395:542-45.

https://doi.org/10.1016/S0140-6736(20)30374-3

PMID:32061313

37. Booth CM, Matukas LM, Tomlinson GA, Rachlis AR, Rose DB, Dwosh HA, Walmsley SL, Mazzulli T, Avendano M, Derkach P, Ephtimios IE, Kitai I, Mederski $B D$, et al. Clinical features and short-term outcomes of 144 patients with SARS in the greater Toronto area. JAMA. 2003; 289:2801-09.

https://doi.org/10.1001/jama.289.21.JOC30885 PMID:12734147

38. Badawi A, Ryoo SG. Prevalence of comorbidities in the middle east respiratory syndrome coronavirus (MERS(oV): a systematic review and meta-analysis. Int J Infect Dis. 2016; 49:129-33. https://doi.org/10.1016/j.ijid.2016.06.015 PMID:27352628

39. Alqahtani FY, Aleanizy FS, Ali El Hadi Mohamed R, Alanazi MS, Mohamed N, Alrasheed MM, Abanmy N, Alhawassi T. Prevalence of comorbidities in cases of middle east respiratory syndrome coronavirus: a retrospective study. Epidemiol Infect. 2018; 147:1-5. https://doi.org/10.1017/S0950268818002923 PMID:30394248

40. Rahman A, Sarkar A. Risk factors for fatal middle east respiratory syndrome coronavirus infections in Saudi Arabia: analysis of the WHO line list, 2013-2018. Am J Public Health. 2019; 109:1288-93. https://doi.org/10.2105/AJPH.2019.305186 PMID:31318592

41. Guan WJ, Liang WH, Zhao Y, Liang HR, Chen ZS, Li YM, Liu XQ, Chen RC, Tang CL, Wang T, Ou CQ, Li L, Chen PY, et al, and China Medical Treatment Expert Group for COVID-19. Comorbidity and its impact on 1590 patients with COVID-19 in China: a nationwide analysis. Eur Respir J. 2020; 55:2000547. https://doi.org/10.1183/13993003.00547-2020 PMID: $\underline{32217650}$

42. Naqvi AA, Shah A, Ahmad R, Ahmad N. Developing an Integrated Treatment Pathway for a Post-Coronary Artery Bypass Grating (CABG) Geriatric Patient with Comorbid Hypertension and Type 1 Diabetes Mellitus for Treating Acute Hypoglycemia and Electrolyte Imbalance. J Pharm Bioallied Sci. 2017; 9:216-220.

https://doi.org/10.4103/jpbs.JPBS 33 17

PMID:28979077

43. Murphy TE, McAvay GJ, Allore HG, Stamm JA, Simonelli PF. Contributions of COPD, asthma, and ten comorbid conditions to health care utilization and patientcentered outcomes among US adults with obstructive airway disease. Int J Chron Obstruct Pulmon Dis. 2017; 12:2515-22.

https://doi.org/10.2147/COPD.S139948

PMID:28883718

44. Pinto $B G$, Oliveira $A E$, Singh $Y$, Jimenez $L$, Gonçalves $A N$, Ogava RL, Creighton R, Schatzmann Peron JP, Nakaya HI. ACE2 expression is increased in the lungs of patients with comorbidities associated with severe COVID-19. J Infect Dis. 2020; 222:556-63.

https://doi.org/10.1093/infdis/iiaa332

PMID:32526012

45. Chen N, Zhou M, Dong X, Qu J, Gong F, Han Y, Qiu Y, Wang J, Liu Y, Wei Y, Xia J, Yu T, Zhang X, Zhang L. Epidemiological and clinical characteristics of 99 cases of 2019 novel coronavirus pneumonia in Wuhan, China: a descriptive study. Lancet. 2020; 395:507-13. https://doi.org/10.1016/S0140-6736(20)30211-7 PMID: $\underline{32007143}$ 
46. Liu $Y$, Yang $Y$, Zhang $C$, Huang F, Wang F, Yuan J, Wang Z, Li J, Li J, Feng C, Zhang Z, Wang L, Peng L, et al. Clinical and biochemical indexes from 2019-nCoV infected patients linked to viral loads and lung injury. Sci China Life Sci. 2020; 63:364-74.

https://doi.org/10.1007/s11427-020-1643-8

PMID:32048163

47. $X u X W$, Wu XX, Jiang XG, Xu KJ, Ying LJ, Ma CL, Li SB, Wang HY, Zhang S, Gao HN, Sheng JF, Cai HL, Qiu YQ, Li $\amalg$. Clinical findings in a group of patients infected with the 2019 novel coronavirus (SARS-Cov-2) outside of Wuhan, China: retrospective case series. BMJ. 2020; 368:m606.

https://doi.org/10.1136/bmj.m606 PMID: $\underline{32075786}$

48. Wu C, Chen X, Cai Y, Xia J, Zhou X, Xu S, Huang H, Zhang L, Zhou X, Du C, Zhang Y, Song J, Wang S, et al. Risk factors associated with acute respiratory distress syndrome and death in patients with coronavirus disease 2019 pneumonia in Wuhan, China. JAMA Intern Med. 2020; 180:934-43.

https://doi.org/10.1001/jamainternmed.2020.0994 PMID:32167524

49. Hanes SD, Quarles DA, Boucher BA. Incidence and risk factors of thrombocytopenia in critically ill trauma patients. Ann Pharmacother. 1997; 31:285-89.

https://doi.org/10.1177/106002809703100302

PMID: 9066932

50. Levi M, Meijers JC. DIC: which laboratory tests are most useful. Blood Rev. 2011; 25:33-37.

https://doi.org/10.1016/j.blre.2010.09.002

PMID:20950905

51. Stéphan F, Hollande J, Richard O, Cheffi A, MaierRedelsperger M, Flahault A. Thrombocytopenia in a surgical ICU. Chest. 1999; 115:1363-70. https://doi.org/10.1378/chest.115.5.1363

PMID:10334154
52. Chong S, Kim TS, Cho EY. Herpes simplex virus pneumonia: high-resolution CT findings. $\mathrm{Br} J$ Radiol. 2010; 83:585-89.

https://doi.org/10.1259/bjr/51409455

PMID:20442279

53. Weaver LK, Behrens EM. Weathering the storm: Improving therapeutic interventions for cytokine storm syndromes by targeting disease pathogenesis. Curr Treatm Opt Rheumatol. 2017; 3:33-48. https://doi.org/10.1007/s40674-017-0059-x PMID:28944163

54. Xu X, Yu C, Qu J, Zhang L, Jiang S, Huang D, Chen B, Zhang Z, Guan W, Ling Z, Jiang R, Hu T, Ding Y, et al. Imaging and clinical features of patients with 2019 novel coronavirus SARS-CoV-2. Eur J Nucl Med Mol Imaging. 2020; 47:1275-80.

https://doi.org/10.1007/s00259-020-04735-9

PMID:32107577

55. Pham T, Brochard LJ, Slutsky AS. Mechanical ventilation: state of the art. Mayo Clin Proc. 2017; 92:1382-400.

https://doi.org/10.1016/i.mayocp.2017.05.004 PMID:28870355

56. Tobin M, Manthous C. Mechanical ventilation. Am J Respir Crit Care Med. 2017; 196:P3-P4. https://doi.org/10.1164/rccm.1962P3 PMID:28707967 


\section{SUPPLEMENTARY MATERIALS}

\section{Supplementary Figure}
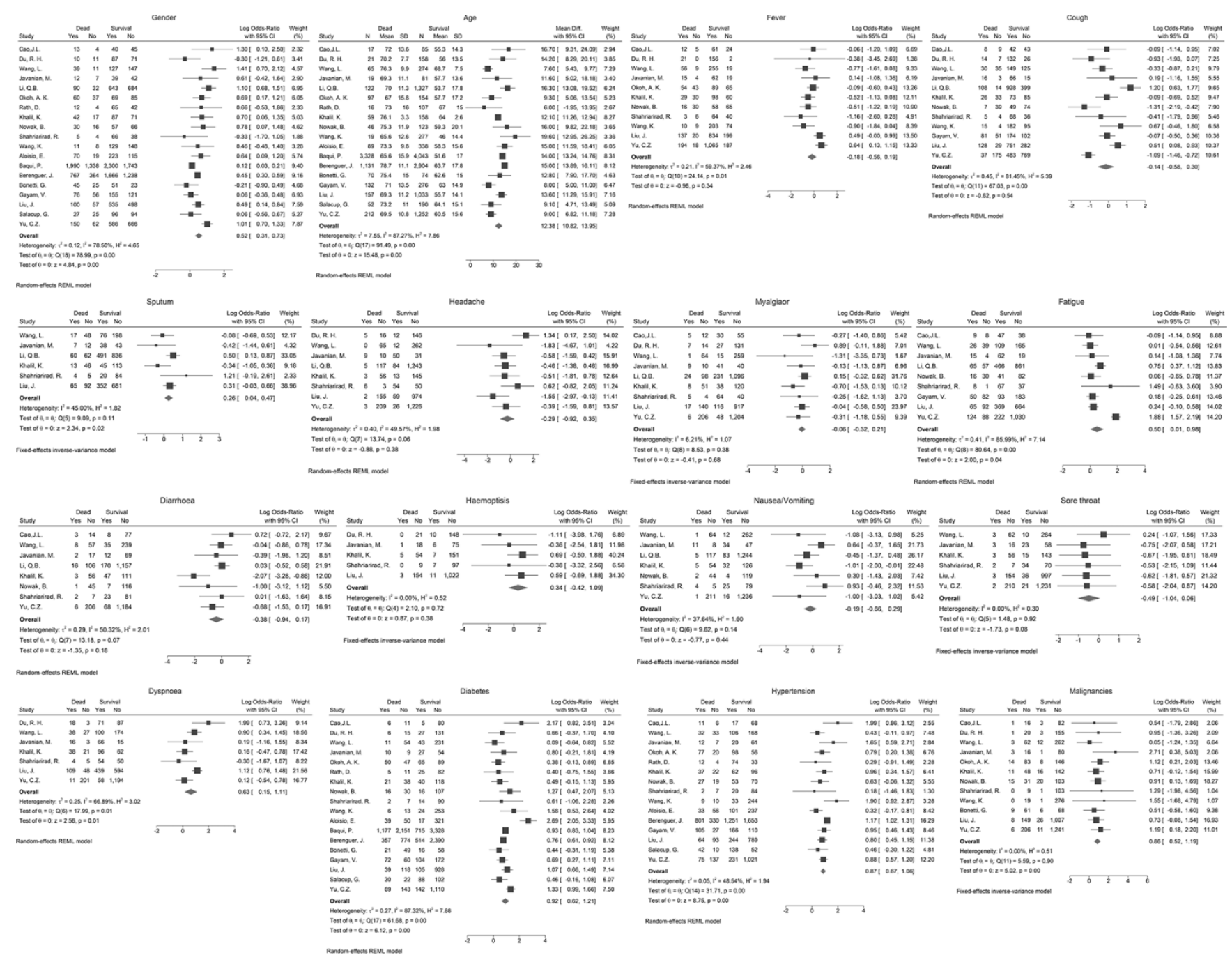

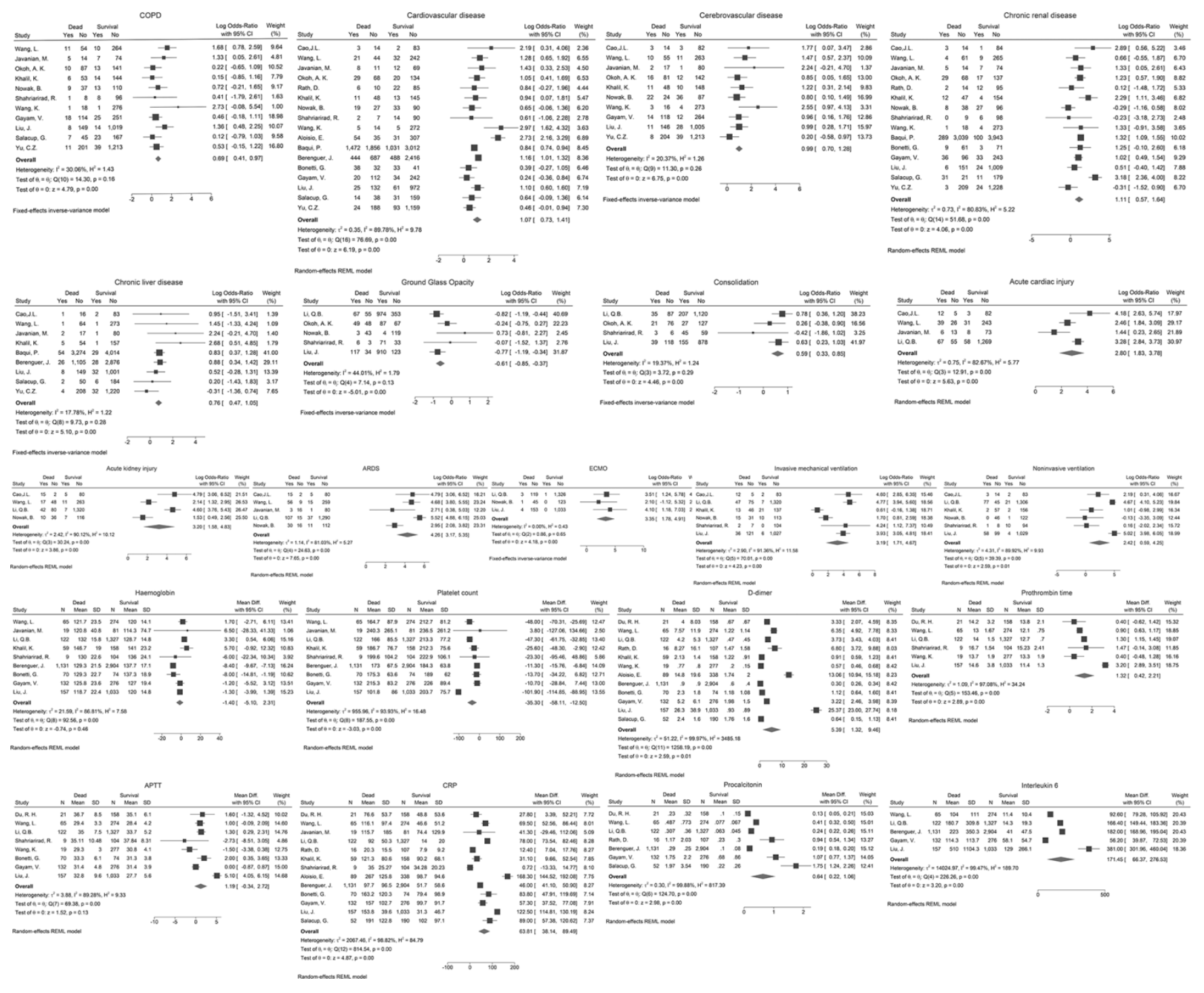

Supplementary Figure 1. Forest plots described in Table 2, 3. 


\section{Supplementary File}

Please browse Full Text version to see the data of Supplementary File 1.

Supplementary File 1. Excluded literatures in the full-text screening step. 